\title{
TRADICIÓN Y RELIGIOSIDAD EN LAS ESTÉTICAS DE LOS MOVIMIENTOS DE VANGUARDIA DE LA PRIMERA MITAD DEL SIGLO XX
}

\author{
TRADITION AND RELIGIOSITY IN THE AESTHETICS OF THE \\ AVANT-GARDE MOVEMENTS OF THE FIRST HALF OF THE $20^{\mathrm{TH}}$ \\ CENTURY
}

DAVID SOLÍS NOVA*

Dr. en Filosofía

Universidad Católica de la Santísima Concepción, Chile

Artículo recibido el or de marzo de 202I; aceptado el o7 de julio de 2021.

*dsolis@ucsc.cl

https://orcid.org/00oo-0003-2462-8436

Cómo citar este artículo:

SOLÍS, D. "Tradición y religiosidad en las estéticas de los movimientos de vanguardia de la primera mitad del siglo XX" en Palabra y Razón. Revista de Teología, Filosofía y Ciencias de la Religión. No I9 JULIO 202I, pp 27-54 https://doi.org/IO.29035/pyr.I9.27 


\title{
RESUMEN
}

El presente artículo es un estudio sobre la concepción que las estéticas de vanguardia de la primera mitad del siglo XX mantienen sobre la tradición, tanto sobre la artística como la cultural, en su amplio sentido. Además, pretende vincular esta concepción con la pretensión religiosa que poseen algunas expresiones artísticas y teóricas que nacieron en el corazón de estos movimientos vanguardistas. Con estas herramientas será posible determinar si existe alguna relación entre los juicios que las estéticas de estos movimientos tenían sobre la tradición, por un lado, y, por otro lado, su búsqueda, acercamiento o experimentación con algún tipo de religiosidad a través de su arte. En base a esta indagación podremos conocer algunos elementos de la especial apreciación que estos movimientos tenían sobre la cultura que les correspondió experimentar.

Palabras claves: vanguardias / estética / tradición / religiosidad / movimientos artísticos

\begin{abstract}
This article is a study on the conception that the avant-garde aesthetics of the first half of the 2oth century hold on tradition, both on the artistic tradition and on the cultural tradition, in its broad sense. Furthermore, it aims to link this conception of tradition with the religious claim that some artistic and theoretical expressions possess that were born in the heart of these avant-garde movements. With these tools it will be possible to determine if there is any relationship between the judgments that the aesthetics of these movements had on tradition, on the one hand, and, on the other hand, their search, approach or experimentation with some type of religiosity through their art. Based on this investigation we will be able to know some elements of the special appreciation that these movements had on the culture that they had to experience.
\end{abstract}

Keywords: avant-garde / aesthetics / tradition / religiosity / artistic movements 


\section{Introducción}

El objetivo de nuestro estudio es indagar la postura de la estética de los movimientos de vanguardia de la primera mitad del siglo XX frente a lo que ellos consideraban tradición, tanto tradición en el arte como la tradición cultural de la cual formaban parte. Además, queremos investigar si puede encontrarse en estas estéticas algún grado de búsqueda y expresión de religiosidad, o, al menos, atención a la experiencia religiosa, que pueda verse reflejada tanto en las obras como en las elaboraciones teóricas de los artistas pertenecientes a estos movimientos. Finalmente, trataremos de verificar si existe alguna relación entre la concepción y valoración que estas estéticas poseían de la tradición y el posible espíritu religioso inspirador que podríamos encontrar tras algunas de estas propuestas estéticas y artísticas. Nuestra hipótesis inicial es que en las estéticas de vanguardia existiría un fuerte rechazo a toda tradición y que esto estaría conectado con la religiosidad que algunos artistas buscaron y rastrearon y, otros, derechamente, experimentaron. Esto nos permitirá conocer de mejor manera el juicio que las estéticas vanguardistas tenían sobre el momento de modernidad que estaban experimentando. Para llevar a cabo tal cometido, se ha utilizado, principalmente, una metodología de revisión bibliográfica y documental.

La primera mitad del siglo XX, en lo que respecta a la creación artística, es especialmente fecunda, llena de variaciones y complejidades. Por ello, es necesario explicitar que hemos acotado nuestro estudio a algunos representantes de estas vanguardias, en los cuales hemos visto mayor presencia de referencias explícitas respecto a la tradición y a la religiosidad. Reconocemos, sin embargo, que esta elección puede ser problematizada. Por ello, aclaramos que nuestro estudio se centra, principalmente, en las estéticas de los movimientos de vanguardia desde los primeros decenios del siglo XX hasta el inicio de la Segunda Guerra mundial, aproximadamente. Hemos tomado como nuestra principal referencia las estéticas de estos movimientos que se expresaron preferentemente en sus variados manifiestos, almanaques y propuestas teórico-filosóficas en algunos casos. Desde ahí hemos ido observando con atención las obras de arte en las que se encarnaron estas estéticas de las vanguardias. También nuestro foco de atención se ha centrado, sobre todo, en las estéticas surgidas en el continente europeo, dentro de ellas, principalmente, aunque no exclusivamente, los movimientos dadaísta, futurista, cubista, surrealista y el arte abstracto. Dentro de estas expresiones, nuestro estudio y lectura se ha enfocado en la pintura y la escultura. Reconociendo estas limitaciones, creemos que es posible 
establecer algunos rasgos comunes a esta forma de pensar el arte y pensar la cultura. Y, sin un ánimo de generalizar a toda costa, creemos que podrían extraerse elementos de juicio y de comparación que servirían para comprender o, al menos, comparar con las otras expresiones de la estética de los movimientos de vanguardia que no han podido quedar expresados en este trabajo.

\section{La batalla contra la tradición}

Entendemos, inicialmente, por vanguardias artísticas una serie de movimientos que promovieron la instauración de inéditas maneras de entender y trabajar el arte, además de horizontes intelectuales e imaginativos nuevos en torno a lo que debíamos esperar del arte. Son propuestas originales para entender la obra y al artista, asumiendo nuevos rangos y potestades para ambos, prácticamente siempre en combate y ruptura con alguna tradición. Con esto se asienta el nuevo arte, generalmente concebido desde el inicio con unas bases teóricas concentradas en sus manifiestos, sobre unos pilares completamente originales y sostenidos sobre la fuerza de la voluntad, una convicción casi apodíctica y la esperanza en las nuevas -y diversas- funciones del arte naciente. Se podría rastrear el origen de estos movimientos en algunos círculos de artistas afines entre sí desde el siglo XIX, pero fue a inicios del siglo XX cuando vemos emerger este espíritu con más fuerza y claridad, por ejemplo, en el dadaísmo, el cubismo, el fauvismo, el futurismo, el arte abstracto, el surrealismo, etc. En todos estos movimientos, y en sus fieles estéticas fundantes, se inaugura una normativa ex novo de las funciones del arte, se problematiza la misma institucionalización del arte, se replantea su esencia y la consistencia metafísica, se podría decir, de la obra de arte y se vuelve a promulgar una nueva vocación para el artista mismo.

El término vanguardia proviene de la nomenclatura militar. Las tropas de vanguardia son las encargadas de explorar el terreno y las primeras en entrar al combate cuerpo a cuerpo. Ellos son la avanzada, la primera línea de ataque, el progreso permanente. La vanguardia está siempre para mover los límites de los desarrollos habidos. No está hecha para preservar, conservar, proteger o mantener. Su avance es permanente. En los artistas de la primera mitad del siglo XX el término les vino bien porque se percibían explorando terrenos y formas nuevas de belleza y expresión. En este sentido, la vanguardia es todo lo contrario 
de la protectora de cualquier tradición ${ }^{\mathrm{I}}$. Debe decir siempre la palabra nueva, debe querer lo que nunca ha sido querido, debe hacer existir lo no sido, no puede preservar tranquilamente lo heredado. En este artículo, entendemos por 'tradición' la herencia de modernidad que reciben las vanguardias a través del arte de los siglos pasados, sin duda, pero también la que reciben a través de diferentes aspectos de la cultura burguesa, tales como la revolución industrial, la mecanización del trabajo, la preponderancia de la ciencia, la burocratización de la vida social y del estado, el escepticismo en los fundamentos de la moral otrora claros, etc. La vanguardia no puede concebirse como las antiguas escuelas artísticas, quienes preservaban unos métodos, unas técnicas y hasta las obras cumbre de un maestro. Ya lo expresaba Marinetti en el Primer manifiesto futurista: "Queremos destruir los museos, las bibliotecas, las academias de todo tipo"2. No pretenden el cultivo de una tradición, que es trabajo en el presente de una herencia pasada, al menos no con la moderna y burguesa con la que inmediatamente conviven. Si ha existido un trabajo sobre esta última tradición, ha sido un trabajo de reacción, más que de prolongación y coronación. Las vanguardias artísticas comparten su intención de distanciarse de lo siempre igual, de los objetos llenos de hábitos, de la belleza ajada y llena de pasado y hacer aparecer una obra como un recién nacido que nadie ha visto antes ${ }^{3}$. ¿No vemos en Klee, en la Bauhaus, en los trabajos de Scheerbart intentos de trabajar desde cero plenamente, casi como creadores de mundos nuevos y, al mismo tiempo, intentos de no dejar huellas, de no dejar herederos? "El amor por la novedad es la cruz simpática" afirma Tzara en su manifiesto dadaísta de I9I84. ¿No es acaso el hierro de la Bauhaus o el vidrio y concreto de los edificios contemporáneos un material sin huellas, sin rastros de pasado humano?

Junto a sus propuestas innegablemente positivas y no reactivas, es imposible no considerar como parte esencial de la propuesta del dadaísmo sus dardos lanzados hacia la institucionalización del arte. Tampoco podríamos entender el cubismo sin su ruptura definitiva con la perspectiva lineal ni al surrealismo lo podríamos comprender del todo sin su oposición tajante a considerar la representación consciente como

\footnotetext{
I Cf. D. BELL. Las contradicciones culturales del capitalismo. Alianza: Madrid, I992, p. 46

2 F. T. MARINETTI. "Le futurisme", Le Figaro, 20 de febrero de 1909. Disponible en: http:// hipermedula.org/navegaciones/marinetti-el-manifiesto-futurista-textos-documental-y-videos/ Consultado el 8 de junio de 2020.

3 Cf. Th. ADORNO. Teoría estética. Akal: Madrid, 2004, p. 37.

4 T. TZARA. Siete manifiestos dada. Tusquets: Barcelona, 20I5, p. II.

5 Cf. W. BENJAMIN. Discursos interrumpidos I. Filosofía del arte y de la historia. Taurus: Buenos Aires, I989, p. I7I.
} 
única fuente de la creación artística. De igual manera, forma parte de la estructura del futurismo el desprecio por la vetusta herencia cultural, su hastío por la serenidad de la composición y su energético llamado a matar el 'claro de luna' y reemplazarlo por la máquina, la simultaneidad y la aceleración. En el arte abstracto vemos también un alejamiento intencionado de la tradición del arte figurativo, que sus representantes interpretan como una liberación de la esclavitud de la creatividad a las formas naturales. Todos estos datos nos parecen innegables muestras de que las estéticas vanguardistas se entienden a sí mismas como una separación radical de la tradición artística inmediata o, al menos, trabajan para que esa separación sea lo más profunda posible y para llevarla hasta sus últimas consecuencias.

Los militantes de la primera línea de exploración deben ser flexibles, no habituados. Su obra debe mantener la jovialidad y frescor de lo recién nacido. Por lo mismo, no se sabe mucho qué hacer con la vejez y la autoridad. La primera línea de ataque necesita soldados jóvenes. De ahí proviene la constante regresión de las vanguardias, su aspecto juvenil, energético y lúdico. Incluso con un poco de esfuerzo podríamos rastrear los movimientos más juveniles, aquellos otros más adolescentes y los derechamente infantiles. Piénsese en las semejanzas entre las propuestas dadaístas y algunas actitudes propias de la infancia ${ }^{6}$. Sentencia Marinetti, por su parte: “ $i C u a n d o$ tengamos cuarenta años, que otros más jóvenes y videntes nos arrojen al desván como manuscritos inútiles!”7.

Por otro lado, los artistas de vanguardia no parten ni quieren ser emisarios de tradición alguna, ellos parten derechamente del yo, de su individualidad. Su arte es fruto de las fuentes últimas de su conciencia, de la raíz prístina de su ser original. Por lo tanto, buscan una composición total que exprese la riqueza y los tesoros no explotados de la personalidad. Frente a la masificación de las costumbres, de los pensamientos y de los objetos fabricados en serie, el artista será propiciador de un acontecimiento nuevo ${ }^{8}$. Si se ha de rescatar algo de la tradición, este encuentro se producirá sólo si pasa la prueba en la inmersión primigenia del yo. Así lo expresa con claridad el artista Joseph Beuys: "Se ha de restablecer un vínculo con lo espiritual, pero ya no a partir de una fuerza

6 Cf. R. POGGIOLI. Teoría del arte de vanguardia. UNAM: México, 20II, p. 49.

7 F T. MARINETTI. 'Le futurisme', Le Figaro, 20 de febrero de i909. Rosenberg refiriéndose a los pintores del Actiong Paiting: "Su tipo no es la del pintor joven, sino más bien la del pintor renacido. El hombre puede estar sobre los cuarenta, el pintor, en cambio, tiene cerca de siete". $\mathrm{H}$. ROSENBERG. The Tradition of the New. Da Capo Press: New York, 1994, pp. 29-30.

8 Cf. E. GOMBRICH. La historia del arte. Phaidon: Londres, I997, pp. 452-453. 
que provenga de la tradición, sino a partir de la propia fuerza, la de uno mismo, la del yo"9. Ya que la vida social y cultural que les rodea les ofrece tradiciones débiles y que dan cada vez menos certezas, ellos buscarán su certeza en el propio contenido de su conciencia.

Según Ortega y Gasset, la cercanía y admiración que sienten los artistas nuevos por el arte prehistórico o no occidental está, precisamente, basado en que este arte carece de tradición ${ }^{\mathrm{IO}}$. Está bien considerado tomar toda la riqueza de algún objeto labrado del neolítico, de los rituales de Oceanía o de la cultura precolombina, pero no se valora tanto, desde la estética vanguardista, tomar algo prestado de nuestros abuelos europeos más cercanos como los griegos. La afinidad espiritual con los primitivos se puede ver, por ejemplo, en toda la estética de Kandinsky y sus compañeros del Jinete azul y en algunos trabajos de Picasso, influenciados por las máscaras africanas (Cf. Cabeza de mujer y Las señoritas de Aviñón de 1907). Encontramos también esta afinidad en la búsqueda de una religiosidad con tintes paganos de Emil Nolde (Cf. Figura y máscara). Klee llegó a sostener que le encantaría desaprender todo lo asimilado en la escuela, ser como un recién nacido, que es otra forma de expresar el deseo de desaprender toda la cultura europea ${ }^{\text {II }}$. Es notoria el ansia de otra forma de vivir más inocente en la obra de tema polinesio de Gauguin y en la inocencia aldeana y preindustrial de las pinturas de Rousseau y Chagall.

En este punto, las estéticas vanguardistas se nos presentan como herederas de las inquietudes modernas, al menos, de la modernidad que les toca experimentar en la primera mitad del siglo XX. Estos tiempos modernos no pueden reposar tranquilamente en un tiempo presente, ya que no pueden trabajar tranquilamente una tradición que les satisfaga. Si hay un rasgo que identifica a la modernidad, pese a las divergencias y contradicciones de ideas y pensamientos, es la valentía intelectual, su carácter rupturista, el radicalismo del pensamiento con el que embiste el pasado contiguo. En este entorno, se pretende que todo hombre olvide cuanto haya aprendido anteriormente, rechazando toda autoridad y desafiando el poder de la tradición ${ }^{12}$. Ante esta incomodidad respecto al pasado, el presente se vuelve problemático ${ }^{13}$. Cada vez más desligado de

9L. CIRLOT. "Rudolf Steiner: del Goetheanum a Joseph Beuys" en L. CIRLOT - L. MANONELLES (ed.). Las vanguardias artísticas a la luz del esoterismo y la espiritualidad. Universidad de Barcelona: Barcelona, 2OI4, p. $3 \mathrm{I}$.

IO J. ORTEGA Y GASSET. La deshumanización del arte. Austral: Buenos Aires, I994, p. 78.

II Cf. V. KANDINSKY - F. MARC. El jinete azul. Paidós: Barcelona, 20I6, p. I2.

I2 Cf. E. CASSIRER. El mito del Estado. FCE: México, I968, p. 199.

I3 "La imagen verdadera del pasado es una imagen que amenaza con desaparecer con todo 
las ataduras con la tradición, el presente moderno es sólo una instancia de aniquilación del mundo viejo y la transición hacia un mundo nuevo. Tal como lo ha planteado Hans Jonas describiendo esta modernidad del siglo XX y comparándola con la ebullición del mercado religioso y de sentido del siglo II y III: "No hay presente en el que morar, sólo la crisis entre el pasado y el futuro, el movimiento afilado entre los dos, balanceándose en el filo de la navaja de la decisión que empuja hacia delante" ${ }^{14}$.

Sin embargo, consideramos que, pese a la incomodidad que la vanguardia expresa por las tradiciones culturales debilitadas con las que se encuentra y por los objetos y costumbres vulgarizados y uniformados de la revolución industrial, es innegable que la audacia de las obras vanguardistas tuvo auxilio de alguna tradición y fue un trabajo compuesto con algunos padres del pasado. Lo vemos en las referencias etruscas y africanas de la obra escultórica de Modigliani (Cf. Cabeza de mujer); en la influencia de la gnosis y la teosofía en la obra de Kandinsky (Cf. Algunos círculos); en la referencia al arte clásico en la obra de Giorgio de Chirico (Cf. Plaza de Italia o Canción de amor), etc. La tradición que tenían más cerca -la tradición moderna occidental y burguesa en el arte y en la cultura- era aquella de la cual se distanciaban, en la medida en que ya no encontraban certezas sólidas en ella, por una serie de motivos que, para encontrarlos, habría que remontarse a las raíces de los siglos modernos y su dinámica interna. Sin embargo, si sus obras encierran un pensamiento que logra conmover aún, estremecer y seguir incentivando nuestra inteligencia y sentidos es porque actualizaron y cultivaron algún tipo de tradición, aunque la fueran a buscar al neolítico, a la religiosidad pagana o a los museos etnográficos. En este sentido, las vanguardias reaccionan, principalmente, a la tradición moderna en la cual han nacido, incluyendo en esta el arte, la cultura y la moral. Por lo tanto, pese a sus declaraciones, estos movimientos artísticos no pueden rechazar absolutamente toda tradición, pues incluso la buscan, pero pareciera una constante ir a buscarla más allá de este presente moderno. Cualquier tradición pareciera más apta y atractiva para nutrir su arte que aquella en la cual han nacido.

presente que no se reconozca aludido en ella". W. BENJAMIN. Tesis sobre la historia y otros fragmentos. Ítaca: México, 2008, p. 39

I4 H. JONAS. La religión gnóstica: El mensaje del Dios extraño y los comienzos del cristianismo. Siruela: Madrid, 2003, p. 354. En relación a esto mismo, Latour dirá: "Los modernos no han sido nunca hasta ahora contemporáneos de ellos mismos". B. LATOUR. "Llamada a revisión de la modernidad. Aproximaciones antropológicas" en AIRB. Revista de Antropología Iberoamericana. Noviembre-Diciembre (2005), p. 18. 
En los movimientos vanguardistas, la voluntad de subversión puede ser tan radical y constante que termina siendo una norma irreversible que termina agotándola y banalizándola. Algunos autores lo han pensado así, al menos. La vanguardia ha llegado a su final, declarará Lipovetsky, "se ha estancado en la repetición y substituye la invención por la pura y simple inflación" ${ }^{15}$. La vanguardia se resquiebra en su propia identidad, luego sólo cabe preguntarse ¿Respecto a qué es vanguardia la vanguardia? ¿Con respecto a qué es la avanzada si pareciera que ya nadie se queda atrás? Pareciera que, avanzado su trabajo de progresar, el estar en la primera línea del arte fuese un nuevo lugar común instaurado como una ley normativa implícita que todos siguen:

"El desorden se convierte en regla cuando se opone en forma deliberada y simétrica a un orden establecido [...] Cubismo y futurismo han llegado a ser hoy día poncifs en el arte decorativo y aplicado, en la escenografía y el moblaje. El funcionalismo arquitectónico se está convirtiendo en clisé en la industria edilicia [...] El Surrealismo llegó al ocaso exactamente cuando algunos de sus procedimientos obtuvieron la aprobación del sensacionalismo en el arte popular e industrial"16.

En el afán de alcanzar lo nuevo, y al vulgarizarse el deseo de novedad, la misma vanguardia se torna consumible, se torna un lugar común, se torna un tópico políticamente correcto. En estricto rigor, sostienen algunos autores, si todo es vanguardia y ya no hay ninguna tradición que salvaguardar, todo se va tornando un simple anhelo difuso de lo novedoso y un aburrimiento de lo viejo e incluso de lo que hasta ayer era nuevo ${ }^{17}$.

También es necesario decir que esta voluntad de iniciar de cero, aunque imposible de alcanzar del todo, como recién señalábamos, marcó a fuego el espíritu y los horizontes de las obras de este período. No sorprende, entonces, que muchas veces este arte muestre fuertes expresiones de nihilismo y vacío, porque es fruto de una sociedad que se percibe cada vez más como sin fundamentos o, al menos, se percibe teniendo bastante dificultad para encontrar tal fundamento ${ }^{18}$. Por ello, encierran sus esperanzas de encontrar tales certezas perdidas en lo nuevo, en lo aún no dicho, en lo aún no visto. Es innegable la cantidad

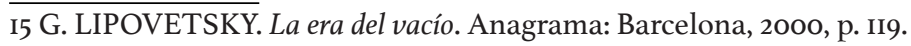

I6 R. POGGIOLI. Teoría del arte..., pp. $94-95$.

I7 Cf. D. BELL. Las contradicciones culturales..., p. 62.

I8 Cf. A. VEGA. Arte y santidad. Cuatro lecciones de estética apofática. Universidad Pública de Navarra: Pamplona, 2005, p. 5I. 
de posibilidades que se abren al cortar lazos con la tradición inmediata y, de esa manera, salir de una sociedad cerrada y estática. Sin embargo, siempre va acompañado este proceso de una sensación de vaciedad y aislamiento ${ }^{19}$. Necesariamente, parecieran decirnos las obras de este período, avanzamos en una trayectoria sin descanso, un peregrinar cultural sin un hogar social al cual volver, sin un remanso de certeza conocido, sin una patria segura que nos espere con un bagaje de riqueza a cultivar ${ }^{20}$. Pese a ello, es en el futuro, en el paso siguiente, en el novum que acontecería en la obra de arte, donde encontraríamos esa certeza que ya no parece capaz de darnos la cultura en cuya herencia se ha vivido. Las nuevas obras de arte son vistas, desde las vanguardias, como las epifanías de los nuevos horizontes vitales.

\section{Vanguardia y reencantamiento}

El arte de los movimientos de vanguardia jugará un rol, más o menos consciente, de re - encantador del mundo. Esto se puede rastrear desde los orígenes del arte moderno, pero en ningún lugar queda más claro que en el arte de las vanguardias y movimientos de la primera mitad del siglo XX europeo. El artista está decidido a trabajar con el misterio. Interpreta que ese desencantamiento es fruto de una ausencia de misterio, de una ausencia del elemento sagrado que hemos perdido por el exceso de influencia y poder del positivismo, el cientificismo y la tecnocracia. Necesita inyectar en el mundo moderno una ingenuidad y un misterio que aparentemente este mundo ha perdido ${ }^{21}$. El misterio querrá hacerse presente en cada una de sus obras, ya sea en la actitud lúdica y onírica del surrealismo, ya sea en los elementos mágicos de la pintura naif, ya sea en la actitud casi sacerdotal y profética del arte abstracto ${ }^{22}$. Este mundo social que se interpreta como cada vez más ajeno, más extraño y cada vez más sometido, no puede ser la última palabra sobre el sustrato esencial de lo real. Un mundo más humano, más propio y cordial se buscará, en diferentes expresiones artísticas, en diferentes más allá: la figura literaria del otro yo, en los viajes más allá de la conciencia, en los sueños, en la cuarta dimensión, en lo demoníaco, en la escritura automática, en lo dionisiaco, etc. Se va en persecución de instancias que puedan servir como refugio y separación de una realidad agotada ${ }^{23}$. Breton, en el primer

I9 Cf. D. BELL. Las contradicciones culturales..., p. 60.

20 Cf. D. BELL, Las contradicciones culturales..., p. 120.

2I Cf. R. POGGIOLI. Teoría del arte..., p. 120.

22 Cf. A. LUQUE. Arte moderno y esoterismo. Secularización y reencantamiento en la cultura contemporánea. Milenio: Lleida, 2002, p. 150.

23 Cf. A. LUQUE. Arte moderno..., p. 174. 
manifiesto surrealista, se expresa con este mismo espíritu:

“¿Por qué no otorgaré al sueño lo que rehúso a veces a la realidad, es decir, ese valor de certidumbre en sí misma, que, en su oportunidad, no esté expuesto a mi repudio? ¿Por qué no he de esperar del indicio del sueño más de lo que espero de un grado de conciencia cada día más elevado? ¿No podría aplicarse también al sueño a la solución de los problemas fundamentales de la vida?" ${ }^{24}$.

A partir de este desarraigo se buscará una nueva tierra firme y, en no pocas ocasiones, derechamente una evasión del presente. Algunas características del arte de este período se prefiguran desde esta insatisfacción e incomodidad: un arte informe o con un cuerpo sin resolución, una tendencia hacia lo volátil, a la desmaterialización, a la disipación de lo dramático e histórico de la vida humana, la reticencia a replicar la naturaleza, el ideal del artista como un ser separado de la vida corriente y, cuando había ocasión de hacerla, la deriva hacia una estética con una base en una ontología mística e idealista. En estas formas nuevas, dirá Worringer, encontrará el artista y todo hombre el único lugar donde descansar de la vasta confusión que le ofrece la imagen del mundo ${ }^{25}$. En ninguna parte vemos reunidos tan claramente estos últimos rasgos como en la estética de los artistas abstractos, tales como Malevich, Mondrian y Kandisnky ${ }^{26}$. Mircea Eliade comprende bien, a nuestro parecer, a Brancusi y su decisión de no trabajar más la escultura en un momento de su vida, como resultado de un paso a un nivel superior de conciencia, después de su célebre escalera al cielo, Columna del infinito de 1938, que implicaba que cualquier otra obra surgida de sus manos resultase baladí. Si el artista moderno está tan involucrado con reencantar el mundo hasta el punto de involucrarse él mismo en esta búsqueda religiosa y mística, una vez que logra esa experiencia sublime, cabe preguntarse si su afán creativo tiene más sentido o no. Si el arte es sólo un vehículo para una experiencia religiosa, esta experiencia podría alcanzarse en algún momento sin recurrir al arte. Literalmente, al subir a la experiencia mística a través de esta escalera que representa el arte, llegados arriba y a buen resguardo, podríamos muy bien tirar de esa escalera ${ }^{27}$. ¿No se podrá prescindir del arte para acceder directamente a esta experiencia?

\footnotetext{
24 A. BRETON. Manifiestos del surrealismo. Argonauta: Buenos Aires, 200I, p. 29.

25 J. MARTÍNEZ BENITO. Kandinsky y la abstracción. Nuevas interpretaciones. Universidad de Salamanca: Salamanca, 20II, p. 82.

26 Cf. J. GOLDING. Caminos a lo absoluto. Mondrian, Malévich, Kandinsky, Pollock, Newman, Rothko y Still. FCE: México, 2003, p. 26.

27 Cf. M. ELIADE. El vuelo mágico. Siruela: Madrid, 20I7, p. I42.
} 
Esta última observación nos muestra cuán involucrados comienzan a estar los artistas, sobre todo de vanguardia, con un reencantamiento del mundo, que entienden casi siempre en clave religiosa, como un retorno a lo sagrado, aunque muchos de ellos no profesen religión alguna ${ }^{28}$. "The conversion has been experienced in secular terms. The result has been the creation of private myths" ${ }^{29}$. En este sentido, su búsqueda cada vez los acerca más a un paganismo genuino, a una religiosidad cósmica ${ }^{30}$. El pintor August Macke dirá: "La forma, para nosotros, está cargada de misterio, porque es la expresión de fuerzas misteriosas. Sólo a través de ellas adivinamos fuerzas misteriosas, el 'Dios invisible'"31. A través de la historia de la humanidad se puede identificar una tendencia a encontrar una explicación misteriosa mediante la utilización de mitos como un recurso concluyente a situaciones de pérdida de certeza ${ }^{32}$, "en situaciones desesperadas, el hombre recurre a medidas desesperadas [...] si la razón nos falla siempre queda la última ratio, el poder de lo misterioso y lo milagroso"33. En la inestabilidad de los sistemas políticos y culturales, de sobremanera evidenciada en los inicios del siglo $\mathrm{XX}$, resurge el misticismo como respuesta, como ultima ratio, como una forma de aplacar la inseguridad y la convulsión de una sociedad que ha perdido su estructura, y en la que se han derrumbado sus ideales y proyectos. En las obras de muchos de estos artistas se buscará encontrar las esencias formales y eternas que configuran todo el universo, generalmente, en configuraciones a-históricas más allá de este mundo o existentes incluso antes de la materialización de este mundo: "Un estilo plástico que no confía ya en las sugestiones de la sombra y de la luz, sino en la severa belleza de la forma contemplada en el espacio eterno y absoluto"34.

Incluso las estéticas vanguardistas han elaborado esta religiosidad que apunta hacia una realidad superior que compite ontológicamente con el mundo real35. Se busca voluntariamente pasar de pintar cosas a pintar ideas. Nuestro arte nuevo se repleta de paisajes interiores y

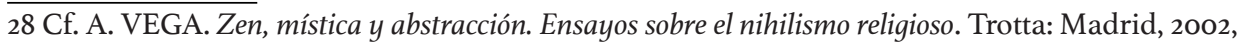
p. III.

29 "La conversión ha sido experimentada en términos seculares. El resultado ha sido la creación de mitos privados". H. ROSENBERG. The Tradition..., p. 3 I.

30 Cf. M. ELIADE. El vuelo mágico..., p. 128.

3I V. KANDINSKY - F. MARC. El jinete azul..., p. 62.

32 Aunque no es la única forma de utilizar el mito. El mito puede conjugarse muy bien como medio de expresión de la razón misma. Cf. H.G. GADAMER. Mito y Razón. Paidós: Barcelona, 2005, p. 22.

33 E. CASSIRER. El mito del Estado..., p. 330.

34 R. POGGIOLI. Teoría del arte..., p. 207.

35 Cf. A. LUQUE. Arte moderno..., p. 363.

Facultad de Ciencias Religiosas y Filosóficas - Universidad Católica del Maule 
autónomos de la naturaleza y de la historia"36. "Yo no pinto las cosas como las veo, sino como las pienso", dirá Picasso ${ }^{37}$. Se ha erigido no como un mero imitador de la naturaleza, sino como un creador de una realidad paralela y sui generis. Jelena Hahl Koch preguntará: “¿Ha habido alguna vez en la historia de la humanidad una situación comparable en la que el artista, en vez de reproducir el mundo, se sienta él mismo como demiurgo y de manera tan evidente (¿o autoritaria?) cree un mundo propio?"38.

Sin embargo, mucho de este retorno a la religiosidad lleva consigo un fundamento irracionalista. No alejándose demasiado de esta especie de ideal de irracionalidad, Schönberg propondrá "perder el lenguaje del mundo para alcanzar lo incomprensible que sólo se puede 'sentir"'39. Kandinsky recomendará a sus discípulos: "Desconfíen de la lógica en el arte" ${ }^{\circ 0}$. Tzara repetirá: "La lógica siempre es falsa" ${ }^{41}$ y Breton describirá el Surrealismo como "un vicio nuevo que, como el haschisch, pueda satisfacer a los consumidores más exigentes" ${ }^{42}$.

Nos preguntamos si esta exaltación de la irracionalidad no tiene su raíz en algunos aspectos irracionales de la misma cultura de la cual nacen los movimientos vanguardistas. La irracionalidad de algunos de los fines

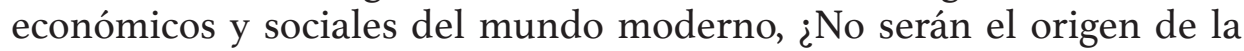
buena fama que empieza a adquirir la irracionalidad en muchos círculos culturales? Como sostiene Wyss: "El progreso industrial va acompañado de la difusión de las sociedades esotéricas que aspiraban a reconciliar ciencias y creencias en sentido gnóstico"43. Por esta razón, algunos autores hablan derechamente de una mitología presente en el corazón del funcionamiento de los siglos modernos: "Al confundir la estética con la cábala y la modernidad con el misticismo, los simbolistas no se engañaban sobre el verdadero carácter de su época, pues justamente es esa confusión el rasgo que define una parte de la cultura moderna"44.

Siguiendo el destino propio de su época, hay en algunos

36 Cf. J. ORTEGA Y GASSET. La deshumanización..., p. 73.

37 L. DE LA CASA et al. Arte del siglo XX. De principios de siglos a la II guerra mundial. Marketing Room: Madrid, 2009, p. I45.

38 J. MARTÍNEZ BENITO. Kandinsky y la abstracción..., p. 247.

39 V. KANDINSKY - F. MARC. El jinete azul..., p. 68.

40 V. KANDINSKY. Escritos sobre arte y artistas. Síntesis: Madrid, 20IO, p. 224.

4I T. TZARA. Siete manifiestos..., p. 22.

42 A. BRETON. Manifiestos..., p. 56.

43 B. WYSS. La voluntad de arte. Sobre la mentalidad moderna. Abada: Madrid, 20IO, p. I89.

44 A. LUQUE. Arte moderno..., p. 355. Cf. TH. ADORNO - M. HORKHEIMER. Dialéctica de la Ilustración. Fragmentos filosóficos. Trotta: Madrid, 200I, p. 74. 
movimientos de vanguardia una cierta hostilidad por la ciencia (Cf. Los anti-mecanismos y las máquinas absurdas en el arte escultórico del Dadaísmo), pero, en otros casos, quieren ser confirmados por ella (Cf. La insistencia de Bretón en asociar el Surrealismo al psicoanálisis ${ }^{45} \mathrm{o}$ la lectura de Dalí a los nuevos descubrimientos sobre la desintegración del átomo, por ejemplo, en su Galatea de las esferas o su Cruz nuclear). Es verdad que la afinidad de algunos artistas por el esoterismo les ha hecho querer fundar sus axiomas creativos en leyes científicas, tal como propone, por ejemplo, la teosofía de Emerson, Swedenborg, Blavatsky o Steiner. Sin embargo, es una ciencia considerada superior a la ciencia positiva en la medida en que estudia realidades más altas. Además, lo que les atrae de esa ciencia, sobre todo de la física de la primera mitad del siglo XX, es su carácter asombroso, misterioso, difícil y sus sorpresas portentosas en comparación a lo que había sido la ciencia en los siglos pasados. Kandinsky recordará su impresión ante los nuevos descubrimientos de la física con las siguientes palabras:

"La desintegración del átomo equivalía, en mi alma, a la desintegración del mundo entero. De repente, los muros más gruesos se derrumbaban. Todo se volvía precario, inestable, desvaído. No me habría sorprendido ver una piedra desvanecerse en el aire y volverse invisible" ${ }^{46}$.

Por todo lo anterior, podemos señalar que el arte de vanguardia, aunque no quiere ser mimesis de la naturaleza ni mucho menos mímesis de un arte académico y burgués y de pensamientos ya hechos, termina siendo, en cierto sentido, mimesis y reflejo de algunos procesos de deshumanización de la sociedad moderna. No siempre ofrece una imagen de una humanidad que defender, sino que reproduce, en ocasiones, la misma deshumanización que se lleva adelante en algunos aspectos de su entorno social y cultural. La sin razón de algunos elementos de la cultura moderna y burguesa es combatida muchas veces con un arte que exalta la sinrazón y la mistificación. Es un arte que conmueve nuestra inteligencia con su novedad y agudeza, nos deshabitúa de los pensamientos ya hechos de una cultura que tiende a la burocratización y a la masificación del tópico, pero tenemos dudas si será este arte la

45 Cf. J. CUEVAS. "El posicionamiento de Sigmund Freud ante el surrealismo a través de su correspondencia con André Bretón" en Espacio, Tiempo y Forma. VII/I (2013), p. 277-293.

46 A. BESANCON. La imagen prohibida. Una historia intelectual de la iconoclasia. Siruela: Madrid, 2003, p. 4I2. En el mismo sentido, se afirmará: "A principios del siglo XX, el descubrimiento de un elemento de indeterminación y relatividad en el sistema científico fue uno de los factores del auge de la abstracción irracional". L. LIPPARD - J. CHANDLER. "La desmaterialización del arte" en R. ALONSO (Coord.). Sistemas. Acciones y procesos. 1965-1975. Proa: Buenos Aires, 20II, p. I08. 
mejor herramienta para superar aquellos aspectos irracionales contra los cuales reacciona. No nos ofrecen los movimientos vanguardistas una imagen con la cuál contrastar ese sin sentido y esa sin razón, más bien, responde a la sinrazón habituada y masificada con una sin razón genial y conmovedora. En la extraordinaria honestidad y novedad de esta reacción ante las convenciones artísticas y culturales de la modernidad que experimentaron se encuentra la grandeza del arte de vanguardia, pero también, creemos, sus límites y el origen de su agotamiento.

Para concluir este punto, diremos que este arte con especial vocación y carácter de re - encantador del mundo, fue un proceso que se vio acentuado por las especiales condiciones de su época, pero no creemos que debamos leerlo como una gran excepción dentro del arte moderno. ¿No ha sido siempre el arte moderno, de alguna manera, una interrupción de la vida ordinaria y una instancia en que el artista nos presta su mirada, su contenido de conciencia para captar un aspecto no visto aún de lo real? Vemos en este período una acentuación del carácter religioso y místico, sin duda, debido a la modernidad que el artista experimenta como agotada en su capacidad de entregar certezas que entreguen significado a la vida, pero, en ningún caso, es un periodo que presente una desconexión absoluta con lo que había venido mostrando el arte moderno respecto a conmocionar el pensamiento y los sentidos.

Lo que sí afirmaríamos como propio de este periodo de los movimientos y estéticas de vanguardia es que tal búsqueda y anhelo de reencantamiento se interpretó como una superación de las capacidades de la razón predominante en la cultura moderna, la razón predominante en su ciencia, en su técnica y en sus instituciones. En este sentido, las estéticas vanguardistas apelan a nuevos sentidos, más allá de la razón, que puedan abrirse al misterio y a una divinidad con rasgos absolutos. Consideramos que el reencantamiento de las estéticas vanguardistas posee una inquietud religiosa evidente. Es una religiosidad que no se acercaría necesariamente a la mayoría de las religiosidades conocidas porque, por ejemplo, muchas veces deriva hacia un exaltado individualismo e irracionalismo y no logra dar el sentido de comunidad que, generalmente, otorgan las religiones tradicionales. Por ello, creemos que la religiosidad que logramos ver en las estéticas de vanguardia nace de una auténtica búsqueda de respuestas espirituales y trascendentes, sin duda. Sin embargo, no se puede separar tal religiosidad de su reacción a las dinámicas de la modernidad de su época y, por ello, conserva todavía las mismas contradicciones internas de esa modernidad: individualismo, búsqueda de significado vital, cuestionamiento de los proyectos de la 
razón y las dificultades de generar comunidad.

\section{La vanguardia y la pretensión de un acontecimiento religioso absoluto}

El secularizado siglo XX ha buscado ininterrumpidamente la experiencia religiosa y el misterio por medio de su arte. En su misma ausencia de imágenes va mostrando su afinidad con una religiosidad cósmica ${ }^{47}$. Es verdad que muchos artistas no tienen fe, pero en sus inquietudes y en sus obras está presente la apertura a lo sagrado. Según Mircea Eliade, ellos están buscando la religiosidad perdida en occidente desde los orígenes del cristianismo ${ }^{48}$. Están abandonando la visión moderna de la naturaleza como un mero objeto natural y en cada objeto material están comenzando a observar una hierofanía y un punto de fuga de fuerzas cósmicas ${ }^{49}$. El artista de vanguardia nos coloca ante los símbolos y trazos de una religiosidad que desconocemos, cuyo contenido es para nosotros aún difuso ${ }^{50}$. Este arte manifiesta una divinidad que todavía no logramos comprender del todo, pero que nos llama a una religiosidad por venir, como el marco vacío de Picabia o el cuadrado negro de Malevich, cuadro que este último colgó, en su primera exposición, en una esquina y levemente inclinado hacia el observador, tal como el pueblo ruso colgaba sus santos íconos para venerarlos.

Siguiendo a Mircea Eliade, si la religiosidad es un espacio para trascender los límites del mundo, la historia y las apariencias ${ }^{51}$, el arte de los movimientos vanguardistas es religioso. Sin embargo, habría que señalar que no es la única manera de entender la religiosidad y sería necesario verificar, además, a qué tipo de religiosidad se acerca este arte en el caso de que esta hipótesis sea correcta. Tomando estos resguardos, afirmaríamos, pese a todo, que esta búsqueda de traspasar los límites del tiempo y llegar a las esencias formales del cosmos se encuentra en el arte de vanguardia como una constante ${ }^{52}$. Asistimos a un esfuerzo sin pausa del artista por liberarse de la superficie de las cosas y penetrar en la materia para develar las estructuras últimas de lo real ${ }^{53}$. Sostiene Duchamp:

\footnotetext{
47 Cf. A. VEGA. Sacrificio y creación en la pintura de Rothko. Siruela: Madrid, 20IO, p. I2. 48 Cf. M. ELIADE. El vuelo mágico..., pp. 128-130.

49 Cf. M. ELIADE. El vuelo mágico..., p. 130.

50 Cf. A. BESANCON. La imagen prohibida..., p. 260.

5I Cf. M. ELIADE. El vuelo mágico..., p. IIo.

52 Cf. A. VEGA. Arte y santidad..., p. 55.

53 Cf. M. ELIADE. El vuelo mágico..., p. I29.
} 
"Es cierto que yo hacía todo lo posible por ubicarme lo más lejos posible de la pintura física 'agradable' y 'atractiva'...El dadaísmo fue una protesta extrema contra ese costado físico, material de la pintura. Se trataba de una actitud metafísica"54.

No quiere ver las cosas como parecen verse desde un ángulo, sino que quiere mostrarlas tal cual son desde una luz eterna, no relativamente bellos sino absolutamente bellos ${ }^{55}$. De esta manera, explorar "aquella oscuridad primordial de la que todo ha salido y ha sido creado" 56 . Se busca una belleza eterna y ya no la belleza transitoria de la naturaleza, ni del espacio ni las imágenes del drama humano ${ }^{57}$. Enfrentamos constantes destrucciones en el arte con el objetivo de recuperar un universo distinto y nuevo, puro, no corrompido por el tiempo y la historia ${ }^{58}$. Declara el manifiesto futurista: "El tiempo y el espacio murieron ayer. Nosotros vivimos ya en el absoluto" 59 . Como en algunos mitos de la religión pagana, hay también en el arte de vanguardia un deseo de aniquilar el mundo, tachando ciclos de imágenes cada cierto tiempo para que se reinicien las fuerzas creativas del cosmos (Cf. Cuadrado negro sobre fondo blanco o Composición suprematista: blanco sobre fondo blanco de Malevich ${ }^{60}$. "Todo movimiento de vanguardia aspira a realizar, al menos en una de sus fases, la empresa de demolición"6r. El futurismo simpatizará con la guerra como un método para higienizar el mundo. Malevich aprueba "la manera en la cual, gracias a su descripción del movimiento y la velocidad, los futuristas lograron destruir 'la totalidad de las cosas'"'62.

En muchas obras de arte pictórico y escultórico vanguardista, lo que vemos es la instauración de un vacío. Ante la ausencia de Dios, no queda más que enfrentarlo con más ausencia, silencio y vacío, un vacío de imágenes para que acontezca su verdadera imagen, un silencio para que emerja y se pronuncie su verdadera palabra. En la ceguera de imágenes pareciera que se esperara vislumbrar lo invisible: "Mondrian

54 L. LIPPARD - J. CHANDLER. "La desmaterialización del arte” ..., p. II2.

55 Cf. R. POGGIOLI. Teoría del arte..., p. 190. Cf. E. GOMBRICH. Arte e ilusión. Estudio sobre la psicología de la representación pictórica. Phaidon: Londres, 2002, p. II8.

56 A. VEGA. Zen, mística..., p. IIo.

57 Cf. E. GOMBRICH. Arte e ilusión..., p. II8.

58 Cf. M. ELIADE. El vuelo mágico..., p. 130.

59 F. T. MARINETTI. 'Le futurisme', Le Figaro, 20 de febrero de 1909.

60 Cf. M. ELIADE. El vuelo mágico..., p. I3I.

6I R. POGGIOLI. Teoría del arte..., p. IO7.

62 J. GOLDING. Caminos a lo absoluto..., p. 58. Más ejemplos de este anhelo de retorno del arte al punto cero, Cf. L. LIPPARD - J. CHANDLER. "La desmaterialización del arte” ..., p. III. 
estaba tratando de descubrir cómo presentar lo universal y lo infinito en pinturas que, en sí mismas, eran tangiblemente finitas"63. El artista inaugura un espacio intermedio de vacío donde pueda encontrarse la nada de Dios y la nada del hombre ${ }^{64}$.

De esta manera, es posible, a través del arte, ir acercándose hacia las verdades eternas de la religión, más allá de los límites de la apariencia. Esta búsqueda que va más allá de la carne y la historia, por ejemplo, más allá de la carne y la historia de Cristo, emparenta a las estéticas vanguardistas con las diferentes doctrinas gnósticas de todos los tiempos. Expulsar a los mercaderes del templo es interpretado como vaciar el alma de toda intención e imagen para que "el alma pueda dar nacimiento al Verbo de Dios" ${ }^{16}$. Las sectas gnósticas cercanas al cristianismo hablarían de alcanzar al Cristo eterno y superar al Jesús de Nazareth de trayectoria temporal. Cristo se desfigura en su humanidad carnal y dramática y se transmuta para la gnosis en un Cristo eterno y atemporal, el verdadero redentor por no tener ya relación alguna con la maldad del mundo creado por el demiurgo, enemigo de Dios. La gnosis se despoja de la carne de Cristo para acceder a la verdadera sabiduría, al alcance de unos pocos, que es el medio verdadero de la salvación ${ }^{66}$. Es una salvación obtenida por el saber de un Cristo interior y conceptual, saber al que muy pocos pueden acceder. Un saber no con los ojos del cuerpo, un camino que va desde lo visible a lo invisible: "Lo decisivo es que la imagen no toma a Dios en tanto creador, sino en su naturaleza abisal no personal, absolutamente desasida y pura: esa es la imagen de la nada que nace en el alma"67.

Este mundo del tiempo y los sentidos es una apariencia, encierra un valor negativo que más bien nos separa de una real experiencia religiosa. Toda experiencia religiosa gnóstica, y buena parte de la estética religiosa de vanguardia, debe romper el velo de Maya de estas apariencias para realmente acceder a lo sagrado ${ }^{68}$. De Paul Klee escuchamos una afirmación que sería extraño haber escuchado en pintores de siglos anteriores al suyo: "La naturaleza vuelve a aburrirme"69. En Múnich, en un taller donde aprende pintura, el joven Kandinsky se asquea del

\footnotetext{
63 J. GOLDING. Caminos a lo absoluto..., p. 36.

64 Cf. A. VEGA. Arte y santidad..., p. 123.

65 A. VEGA. Arte y santidad..., p. I04.

66 Cf. F. CULDAUT. El nacimiento del cristianismo y el gnosticismo. Propuestas. Akal: Madrid, 1996, p. 52.

67 A. VEGA. Arte y santidad..., p. I30.

68 Cf. F. CULDAUT. El nacimiento del cristianismo..., p. 46.

69 A. BESANCON. La imagen prohibida..., p. 393.
} 
desnudo que debe pintar: "En muchas posiciones, las líneas de algunos cuerpos me resultan repelentes" ${ }^{70}$. En muchos artistas alrededor de Franz Marc y el Jinete azul se percibe ese rechazo a la naturaleza, a favor de una sobrenaturaleza, un rechazo gnóstico del mundo. Marc afirma: "La naturaleza es horrible y nefasta, una amarga cárcel del espíritu"

La abstracción en este tipo de arte tiene su origen en el rechazo de los excesos voluntaristas de la sociedad de la que se es parte y que se extrapola a un rechazo de toda la realidad: "El impulso de la abstracción nace del rechazo al propio ser creado" 72 . Se rechaza al demiurgo malvado creador de este mundo y estas apariencias, y se va tras el Deus absconditus. Intencionadamente alejan su vista del drama humano, de la especial historicidad de todo contenido humano, con el objetivo de acercarse a una supra-realidad: "En su fuga de lo humano no le importa tanto el término ad quem, la fauna heteróclita a la que llega, como el término a quo, el aspecto humano que destruye"73.

El artista se presenta como modelo de espiritualidad y como puente hacia una nueva época de gran espiritualidad. De alguna manera es el anunciador de esta nueva época, su legislador, profeta y sacerdote ${ }^{74}$. Si bien la vanguardia encierra unos contenidos que sólo unos pocos pueden comprender y, diríamos, está pensada para una pequeña elite ${ }^{75}$, tiene como objetivo anunciar un contenido que, si bien ahora llega sólo a unos pocos iniciados, es el contenido que regirá a todo el pueblo del mañana. Este arte, por ello, busca impactar, conmover, sacudir, convertir las conciencias hacia una disponibilidad y apertura nueva, "como en una conversión religiosa" ${ }^{76}$. Más que una obra es un acto de provocación y conmoción del pensamiento ${ }^{77}$. Por lo mismo, en el Jinete azul se compara al Juan Bautista de El Greco con la Torre Eiffel vanguardista de Delaunay (Campos de Marte: la torre roja $)^{78}$. El arte de vanguardia, ya sea en la pintura como en la arquitectura, es el anunciador de nuevos y mejores tiempos en cuanto más espirituales. Así como Juan Bautista anunció la llegada del

7 70 A. BESANCON. La imagen prohibida..., p. 4I2.

7I B. WYSS. La voluntad de arte..., p. 2 IO.

72 A. VEGA. Zen, mística..., p. Io8.

73 J. ORTEGA Y GASSET. La deshumanización..., p. 6I.

74 Cf. V. KANDINSKY. De lo espiritual en el arte. Paidós: Barcelona, 20IO, p. I04.

75 Cf. J. ORTEGA Y GASSET. La deshumanización..., p. 47. Cf. B. WYSS. La voluntad de arte..., p. I9I.

76 D. BELL, Las contradicciones culturales..., p. 56.

77 “El acto de provocación mismo ocupa el puesto de la obra". P. BÜRGER. Teoría de la vanguardia. Península: Barcelona, 2000, p. II3.

78 V. KANDINSKY - F. MARC. El jinete azul..., pp. 74-75. 
Hijo de Dios, la arquitectura y el arte de vanguardia anuncian la era del Espíritu, una tercera era definitiva de hombres espirituales. Su relación con la historia y el mundo se limita a la elaboración de un proyectado futuro más espiritual y menos materialista. Esta proyección permanente hacia un futuro convierte al artista en un verdadero profeta y anunciador de nuevos tiempos como podemos apreciarlo en Kandinsky, Schönberg, Mondrian, por ejemplo, que nos traen la buena nueva de la época de la gran espiritualidad'79 (Cf. Evolución, Mondrian I9II). El arte es un medio "para la práctica meditativa hacia ese futuro que haría redundantes sus propios artefactos"

Esto explica la especial vocación y tarea que el artista de vanguardia verá en su labor, que no será un simple oficio entre otros, ya que el artista estará especialmente implicado en su obray en su elaboración encontrará sentido toda su existencia. Es el vehículo no sólo para crear, sino para trascender los estrechos límites de la naturaleza y relatarnos lo que hay más allá de ella ${ }^{81}$ : "When a tube of paint is squeezed by the Absolute, the result can only be a Success" ${ }^{\prime 2}$. Más que un artista es un testigo ${ }^{83}$ : da testimonio de una forma de vida, de una búsqueda de los aspectos superiores de la realidad. Charles Morice escribió: "Todo verdadero poeta es por instinto un iniciado" ${ }^{4}$. En algunos casos es un teúrgo que no se limita a representar lo divino, sino que lo crea, lo manipula y lo manifiesta ${ }^{85}$. Al igual que la función de los antiguos chamanes, va en viaje a lo sobrenatural para traernos un poco de esa experiencia transfigurada en obra de $\operatorname{arte}^{86}$. El testimonio y este viaje interior es lo fundamental. Incluso podríamos decir que la obra es sólo un medio para que suceda un acontecimiento, una revelación. Emil Nolde dirá: "Mis grabados no

79 Cf. V. KANDINSKY. De lo espiritual..., p. I08. De acuerdo con Düchting, Kandinsky y parte importante del grupo que elaboró El jinete azul estudiaban y discutían las doctrinas de Joaquín de Fiore, principalmente, la obra 'La tercera revelación'. H. DÜCHTING. Wassily Kandinsky. Una revolución pictórica. Taschen: Madrid, 1996, p. 46.

8 o B. WYSS. La voluntad de arte..., p. 8I.

8I Cf. D. BELL, Las contradicciones culturales..., p. 50.

82 "Cuando un tubo de pintura es exprimido por el Absoluto, el resultado sólo puede ser un éxito". H. ROSENBERG. The Tradition..., p. 34 .

83 Cf. J. L. NANCY. El arte hoy. Prometeo: Buenos Aires, 20I4, p. 28. "Estos artistas están mucho más 'adentro' de sus obras que otros". L. LIPPARD - J. CHANDLER. "La desmaterialización del arte" ..., p. II5.

84 A. LUQUE. Arte moderno..., p. 9I.

85 Cf. A. BESANCON. La imagen prohibida..., p. 388.

86 Cf. A. VEGA. Zen, mística..., p. 57. Clifford ha sostenido que el Surrealismo ha reemplazado al artista creativo por: "El genio-shamán que descubre realidades más profundas en el dominio psíquico de los sueños, los mitos, las alucinaciones, la escritura automática". J. CLIFFORD. Dilemas de la cultura. Antropología, literatura y arte en la perspectiva posmoderna. Gedisa: Barcelona, 200I, I80-I8I. 
están construidos mentalmente; surgen" ${ }^{87}$. El cuadro no es una cosa, sino un acto $^{88}$.

"The canvas began to appear [...] as an arena in which to act -rather than as a space in which to reproduce, re-design, analyze or 'express' an object, actual or imagined. What was to go on the canvas was not a picture but an event" 89 .

El lienzo es el campo de acción de un 'Alguien' que tal vez no sea el mismo pintor, mero puente del Absoluto. Más que actuar en el lienzo, son actuados y arrojados sobre él. Se rompe con todo objeto y queda el acto revelador, casi litúrgico, casi la epifanía de un 'momento sin tiempo':

"Toda la sucesión contemporánea de formas parece organizada por el acontecimiento, como si impresionismo, simbolismo, expresionismo, cubismo y todos los 'ismos' fueran arrastrados cada vez más de prisa, a su pesar, hacia ese punto de ruptura, hacia una catarata sin fondo" 90 .

El valor del arte pasa de la obra al artista, pareciera que la verdadera obra es el artista mismo y su testimonio. Lo que se revela en el lienzo es la profundidad y abismo de su propia conciencia. Cada obra es el acontecimiento y el acto de viajar hacia el fondo de su ser auténtico. Es un acontecimiento más espiritual y privado que un acontecimiento histórico. Es un arte que pone un énfasis muy fuerte y casi exclusivo en lo conceptual y en el cual el objeto artístico, en su consistencia física, puede empezar a resultar casi obsoleto ${ }^{91}$. No importa tanto el resultado como el proceso, el viaje, la búsqueda, la experimentación que, como un viejo alquimista, se utiliza para producir el misterio, el portento ${ }^{92}$. Duchamp con su ready-made se reviste de las antiguas capacidades de un alquimista para tomar un objeto ordinario y elevarlo a la categoría de obra de arte y origen de múltiples significaciones ${ }^{93}$. Es imposible no

87 J. BRIHUEGA. "Las vanguardias artísticas: teorías y estrategias" en V. BOZAL (ed.). Historia de las ideas estéticas y de las teorías artísticas contemporáneas II. La balsa de Medusa: Madrid, 20IO, p. 235.

88 Cf. D. BELL. Las contradicciones culturales..., p. 125.

89 "El lienzo comenzó a aparecer...como una arena en la cual actuar -más que un espacio en el cual reproducir, re-diseñar, analizar o 'expresar' un objeto, actual o imaginario. Lo que iba a ocurrir en el lienzo no era ya una pintura, sino un evento". H. ROSENBERG. The Tradition..., p. 25. 90 A. BESANCON. La imagen prohibida..., p. 464.

9I L. LIPPARD - J. CHANDLER. "La desmaterialización del arte” ..., p. IO7.

92 Cf. D. BELL. Las contradicciones culturales..., p. 56.

93 Cf. I. GÓMEZ. Geometría y esoterismo. El edificio del Goetheanum. Diseño: Buenos Aires, 2015, p. 98. 
asociar los diversos happening y performances del arte contemporáneo, que iniciaron las vanguardias, con actos litúrgicos que quisiesen romper con un tiempo sagrado el monótono avance del tiempo ordinario del trabajo y las tareas cotidianas (Cf. La fotografía de Hugo Ball de 1916 como Obispo cubista).

Una de las grandezas del arte y estética vanguardistas es haber pensado el arte no ya desde el sustancialismo, sino desde la noción de acontecimiento, pensando la obra de arte como el acaecer de una novedad no prevista ni predecible, como el evento de lo no pensado, de lo no visto, de lo no dicho aún. No obstante, el acontecimiento vanguardista, pese a ser el acontecimiento una categoría estrictamente temporal, es interpretado como un advenir de lo trans-temporal y absoluto. Es un acontecimiento, paradójicamente, más allá de la historia o que, mejor dicho, abre una brecha en la historia para que ingrese lo eterno en lo temporal, lo absoluto en lo relativo. Es innegable que su nueva propuesta saca al arte de la trayectoria de la creación de meros objetos sustancializados, ya hechos y acabados, y coloca a la obra de arte en el camino al menos, de un pensamiento y un evento en movimiento, no lineal, sino haciéndose y reiniciándose de manera constante.

\section{Conclusiones:}

I.- Las estéticas de los movimientos vanguardistas tienen como una de sus principales motivaciones un pathos de distanciamiento respecto a lo que podríamos llamar tradición moderna. Sin negar sus caracteres propositivos y originales, las estéticas de vanguardia mantienen una dosis fuerte de reacción frente a la herencia de modernidad que experimentan. Este distanciamiento de la cultura moderna es, principalmente, distanciamiento del positivismo, de la debilidad de la religiosidad tradicional para dar significado, de la burocratización y tecnificación del trabajo, de la voluntad de domino industrial y de la sistematización del pensamiento, entre otros aspectos. Incluso en el futurismo, donde pareciese que encontramos una exaltación del progreso industrial y técnico, se aspira a una nueva era, donde máquinas, velocidad e industrialización generen una nueva forma de vida que vaya dejando atrás la anterior. Consideramos que el futurismo es también un tipo de alejamiento de la tradición vía aceleración hasta las últimas consecuencias de la sociedad técnica, industrial y capitalista. Sostiene el manifiesto: “¡Nos encontramos sobre el promontorio más elevado de los 
siglos! ¿Por qué deberíamos cuidarnos las espaldas?”94.

Aunque no explica la totalidad de la existencia de las estéticas de estos movimientos, creemos que la explica en parte el hecho de que se mueven dentro de un gran malestar de la cultura, en la medida en que no se sienten cómodas con su tradición anterior, no la reconocen como su progenitora legítima y, desde esta orfandad, plantean muchas de sus creaciones como búsquedas de un nuevo fundamento. El rechazo de sus padres más cercanos, es decir, la tradición y cultura occidental moderna, motiva a estas estéticas a buscar alguna herencia y una tradición sobre la cual trabajar. Por esta razón, su búsqueda los lleva a explorar y cultivar tradiciones más distantes, pero percibidas como más significativas, como los gnosticismos en sus variadas facetas, algunos elementos del misticismo, las formas del arte y artesanía primitivos, los objetos rituales de la cultura africana, etc. En toda la búsqueda de las estéticas de vanguardia se manifiesta ese rechazo a su tradición más cercana, pero también un fuerte anhelo de fundamento, un anhelo de patrimonio al cual cultivar. Cuando esta búsqueda fracasa, se enaltece el individuo como único fundamento, como una especie de causa sui, originador de nuevos mundos y de un reinicio ex novo.

2.- En las estéticas de los movimientos de vanguardia hay una nueva actitud hacia la naturaleza, la que ya no se observa con la benevolencia de una fuente inspiradora de formas, figuras y vida, sino como un velo que debe ser traspasado para alcanzar las formas directrices y paradigmáticas que la determinan. Creemos ver en muchas de estas estéticas la búsqueda del fundamento de lo real y, por ello mismo, una despreocupación -que a veces se tradujo en franco desprecio- por la naturaleza fundamentada. Lo que les interesó fue el arquetipo divino que podría estar tras la naturaleza. En muchas de estas estéticas prima el tachar, superar, desfigurar, silenciar las formas y figuras originadas de la naturaleza. Se observa en ellas, también, una artística destrucción del mundo para que emerja con novedad y nuevos bríos una nueva creación -la obra de arte de vanguardia- bautizada con las aguas y las manos del fundamento divino olvidado y oculto tras la naturaleza. Como decíamos en el punto anterior, ante una tradición (y dentro de ella las religiones tradicionales) que ya no satisface y no da sentido de comunión, se avanza hacia una búsqueda individual de una religiosidad, en busca de un Deus absconditus hiper-trascendente que logre reencantar un mundo que ha perdido su luz y significación, en cuanto manipulado

94 F. T. MARINETTI. 'Le futurisme', Le Figaro, 20 de febrero de 1909. 
y prostituido por el positivismo, la tecnificación, la burocratización de la sociedad, etc. Nos atreveríamos a decir que son estéticas huérfanas de un Padre celestial y terrenal, sin el patrimonio de una herencia que trabajar y que, por ello, buscan en su reemplazo categorías que logren superar e ir siempre más allá de la gramática de la naturaleza, del tiempo, la historia y la carne con el objetivo de buscar una nueva patria de luz. Ante una tierra inhóspita buscarán una patria eterna, alejada de estas tierras finitas y sin encanto, abandonadas por todos los dioses. Por esta razón, su divinidad será afásica, impersonal, eterna, infinita y llena de misterio. Se responde a la pregunta por el sentido trascendente del mundo, pero se responde con una divinidad con la cual ya no se puede establecer alianzas y sociedad, que más bien exalta el viaje individual del artista que la constitución de una civilidad temporal. En este punto, ya podríamos responder que existe, efectivamente, una relación entre la noción que las estéticas de vanguardias tienen de tradición y su acercamiento, en algunos casos, a expresar en clave religiosa algunas de sus obras de arte. Esta clave religiosa se acerca a los parámetros de la gnosis ${ }^{95}$ por su noción de divinidad hiper-trascendente, por su intento de superación de la naturaleza y la historia, por su convencimiento de que algunos iniciados (los artistas vanguardistas mismos) tienen acceso a este eón-pleroma más allá del entendimiento ordinario de los saberes temporales ${ }^{96}$. Ahora bien, al entregar al arte esta tarea de búsqueda de sentido trascendente y de significado vital, las estéticas vanguardistas dejan abierta la puerta para que, en algún un momento, se prescinda de la obra artística (quedando con el estatus de simple medio para la vía religiosa) y se vaya en dirección de la experiencia religiosa misma. Estas estéticas y sus frutos dejan planteada la pregunta para las generaciones futuras de artistas sobre la posibilidad de la 'muerte' del arte en cuanto obra-cosa y la trasformación de la obra en acontecimiento y testimonio.

3.- Se debe valorar a las estéticas de las vanguardias la promoción de figuras nuevas, de formas, colores y percepciones originales que lograrán conmover siempre el pensamiento. No podemos negar el carácter positivo y original de su propuesta en cuanto han pensado el arte y

95 El congreso de Mesina en I966 zanjó, en gran medida, aunque no totalmente, el debate terminológico llamando 'gnosticismo' a las corrientes religiosas surgidas del hervidero de ofertas de sentido del siglo II y III de nuestra era, y dejando el término 'gnosis' para cualquier doctrina que surgiera en otro momento de la historia y que tuviera como elementos centrales la idea de un Dios super trascendente, la superación de la naturaleza y la historia, y la salvación por medio del conocimiento de una elite de individuos bien señalados. Cf. C. MARKSCHIES. La Gnosis. Herder: Barcelona, 2002, p. 33. Cf. F. GARCÍA BAZÁN. Gnosis: La esencia del dualismo gnóstico. Castañeda: Buenos Aires, I978, p. 3I.

96 Cf. C. MARKSCHIES. La Gnosis..., p. 37 - 38. Cf. F. CULDAUT. El nacimiento del cristianismo..., p. 7 - 8 . 
lo han hecho crecer, casi explosivamente, como en pocos momentos de la historia. Como decía Péguy, un verdadero pensamiento no es el que establece una verdad definitiva, sino que es aquel que produce una conmoción, un estremecimiento ${ }^{97}$. Las estéticas vanguardistas y sus obras han producido esta conmoción y la siguen produciendo, sin duda. En primerísimo lugar, hay que valorizar el que hayan pensado la obra de arte como un acontecimiento, como un evento no previsible ni deducible de elementos anteriores. Con esto abre un terreno fértil para pensar el arte desde nuevas lógicas, diríamos, no sustancialistas. Afirmado esto, hay que señalar que mucha de esta originalidad que resaltábamos se agota, en ocasiones, precisamente, en la medida en que trabaja en base a la reacción de una tradición anterior. La reacción queda atada y fijada a aquello en base a lo que reacciona. En este sentido, su justo juicio crítico de la modernidad se va limitando, acortando e inevitablemente va replicando, no ya la naturaleza, no ya el arte anterior, pero sí algunos aspectos de la cultura moderna de la que pretendía alejarse. Es verdad que en muchas ocasiones es un grito de protesta, pero un grito no alcanza a ser todavía un juicio y una comprensión completa. Esa rebeldía termina moviéndose en los mismos parámetros de la modernidad por la cual protesta. El afán de novedades en el arte se conjuga demasiado bien con la exigencia de novedad en los productos de consumo. Su tendencia a lo abstracto se armoniza bastante con la vaciedad y abstracción de muchas relaciones humanas en una sociedad burocratizada. Su simpatía por el irracionalismo no se aleja demasiado de un sistema fundado en un uso irrazonable de la razón, reducida a un dominio y un cálculo desligados de fines humanizadores. Su rechazo a la tradición continúa el desapego y desprecio que el desarrollismo impone a cualquier forma de tradición con la excusa del progreso permanente. Si se puede arrasar una cultura entera con la retroexcavadora moderna y denominarlo progreso continuo, por qué no se podrá llamar arte a la exposición de un urinario en un museo, tal como lo hizo Duchamp (Cf. La fuente de 1917). No negamos que la estética de los movimientos de vanguardia no tenga un juicio crítico y razonable sobre la cultura que hereda, sino que su pathos de distanciamiento termina replicando muchos aspectos que critica y haciendo que esta crítica se agote muy pronto en su contenido. Las estéticas de los movimientos de vanguardia todavía quedan atadas a aquello que rechazan y no ofrecen una solución cívica a los problemas que, con justa razón, describen y que quisieran superar. Por ello, en política tienden a lo utópico y en religiosidad buscan un más allá que desemboca en el más adentro gnóstico de una introspección que

97 CH. PÉGUY. Nota conjunta sobre Descartes y la filosofía cartesiana. Emecé: Buenos Aires, 1946, p. 336. 
exacerba la individualidad del artista.

Esto no quiere decir que sea inútil todo el legado del arte y estéticas de vanguardia. Observar este tipo de arte es como hundirse en los ríos subterráneos que vivifican toda la actividad de estos ajetreados siglos. Es una oportunidad perfecta para conocer las aspiraciones e inquietudes últimas de este período y sus más altas convicciones, por ello mismo, es una manifestación, traducida en belleza, sensibilidad, astucia y genialidad, de la fuerza de intenciones que ha movilizado a la modernidad. Sin embargo, el arte de vanguardia es menos capaz de rebatir la irracionalidad de algunos aspectos de la vida moderna que de simplemente replicarlos, reaccionar ante ellos manteniéndose atado a su trayectoria, y darles una expresión hiperbólica y conmovedora a los sentidos y a la inteligencia. En este sentido, es más útil para el diagnóstico y develamiento de las contradicciones del momento moderno que les tocó experimentar que para su superación.

4.- Nos atrevemos a concluir, gracias a todo lo revisado anteriormente en torno a las vanguardias, que este sujeto deseoso de religiosidad, incómodo con un presente todavía sometido a la razón instrumental y proyectado hacia una nueva era en base a una reacción de su modernidad que no siente como verdadera herencia, no encontrará satisfacción mientras no trabaje una real tradición, no para mantenerla intacta y momificarla, sino para actualizarla y rejuvenecerla en el presente. Difícilmente podrá entenderse a sí mismo y establecer relaciones auténticas si no es trabajando en común una tradición con otro y no contra otros ${ }^{98}$. De otra manera, siempre permanecerá el malestar con la cultura que experimenta. No hay presente, ni originalidad, ni novedad plena sin este trabajo con la memoria, el trabajo de hacer presente y nueva una determinada herencia, manteniendo el mismo espíritu, creemos, que inspiraba a Pavese al decir: "Lo asombroso verdadero está hecho de memoria, no de novedades"99. Más que rechazar toda tradición por el hecho de serlo, consideramos que se deduce de todo lo anteriormente estudiado que la única forma de un acontecer nuevo, original y personal de nuestra historia es entenderla como un trabajo, con beneficio de inventario, en base a los mejores frutos de la modernidad de la que somos herederos ${ }^{100}$, un trabajo colaborativo, deliberado, solidario y con beneficios univerales, sin exclusiones. Sólo así habría identidad, sentido

98 CH. PÉGUY. El frente está en todas partes. Nuevo inicio: Granada, 20I4, p. 70.

99 C. PAVESE. El oficio de vivir. Seix Barral: Barcelona, I993, p. 235.

Ioo Cf. B. LATOUR. "Llamada a revisión de la modernidad. Aproximaciones antropológicas" ..., 19-20. 
y arraigo en una patria cultural.

Por ello mismo, el arte podría encontrar nuevos espacios de creación en la medida en que se entienda menos como un arte de perspectiva individual, de sistematización personal, de testimonio subjetivo y de búsqueda de una originalidad a ultranza, y más como un arte que es trabajo com-puesto, trabajo de una herencia moderna común, que es trabajo enriquecedor de un pensamiento que es también compuesto y colaborativo. 
